\title{
El marco ideológico de la expansión española por el norte de Africa
}

\author{
MIGUEL ANGEL DE BUNES IBARRA \\ Centro de Estudios Históricos \\ CSIC
}

Reseñar, aunque sólo sea en el breve espacio de estas líneas, el marco ideológico y de pensamiento de la época en el que se desarrolla el paso de las embarcaciones y los soldados hispanos al otro lado del estrecho de Gibraltar es dar una explicación de los caracteres de esta empresa exterior de la Monarquía Hispánica. La historiografía tradicional, tanto la de los investigadores de las relaciones internacionales de los Austrias como de los africanistas, ha partido del final del proceso de la "Reconquista" como el inicio de la ocupación del Magreb. Sin poder negar en ningún momento la trascendencia de la conquista del reino de Granada en la formación de la política exterior española y en la creación de un marco ideológico para la realización de la aventura africana, cuyo influjo directo dura hasta 1516 , reducir espacial y temporalmente los antecedentes y las razones de las acciones de los militares y religiosos que atraviesan el mar de Alborán supone simplificar y limitar excesivamente la cuestión.

Para la empresa africana de la Monarquía en la Edad Moderna, que no así para las acciones de los castellanos, aragoneses y los portugueses anteriores a la conclusión de la recuperación de los territorios en manos de los 
musulmanes en la península lbérica, contamos con una abundante bibliografía (1). Ésta se centra mayoritariamente en los aspectos militares, estratégicos y religiosos, condenando a escasas referencias, situadas siempre en las primeras páginas, a los ideológicos y políticos en el mantenimiento de la guerra con los habitantes del continente vecino. Por desgracia, carecemos de trabajos de carácter general (2) y de nuevas series documentales para seguir ahondando en las claves de la dinámica mediterránea tras la unificación de reinos, tanto para aspectos concretos como para definir el marco general. El abandono tangible de estudios sobre la expansión hispana contra el islam en los repertorios bibliográficos, y por consiguiente de nuevas líneas de investigación, resulta extraño por la gran cantidad de series manuscritas sin publicar que se conservan en los archivos españoles, por la importancia de algunos de los procesos que se litigan en estas acciones armadas y por el momento histórico y cultural en que se realiza. Referir que el paso del estrecho resultó una empresa de muy poca importancia en comparación con las otras áreas donde la Monarquía estaba enzarzada en la lucha de sus intereses o que f'ue una línea de la política exterior que mostró rápidamente su fracaso, es dar un juicio acertado pero utilizando los datos a "posteriori". Es, asimismo, corroborar una idea que ya se encuentra en algunos textos y memoriales de los años en los que se está realizando esta expansión. Establecer la falta de unas directrices estables sobre la presencia hispana en el Magreb para toda la Edad Moderna, o explicar el rápido abandono de las expectativas de conquista, supone también referir formas de actuación evidentes o recopilar las entradas en África que se saldan con estrepitosos fracasos.

La limitación de las acciones concretas y decididas de la política en África contrasta. sin embargo, con las aspiraciones populares y el enorme reflejo que tienen en la literatura del "Siglo de Oro" los acontecimientos que se desarrollan en el otro lado de las costas andaluzas y levantinas. poniendo en evidencia la importancia que se da a esta cuestión en los círculos alejados del poder (3). El enfrentamiento con el islam será utilizado ampliamente por la propia Monarquía Hispánica para legitimarse ante sus súbditos y ante el resto de los reyes europeos. Ello también pone de mani- 
fiesto que, aunque estamos reseñando una empresa fallida y sin esperanzas de éxito, está sustentada en unas justificaciones y un marco ideológico que la hacen cara a la mayor parte de los oyentes del momento y al propio poder que la formula. Es, asimismo, imprescindible para unos reyes que se presentan ante sus contemporáneos como los defensores de la religión católica y de los valores, formas de vida y organización del poder imperantes en Europa occidental ante un enemigo exterior. Simplemente por la implicación de todos los elementos de la sociedad de estos siglos en la empresa africana y por la pervivencia de algunos de los logros de la misma hasta la actualidad, merecía y merece que se hubiera estudiado de una manera más concienzuda y persistente.

La empresa africana representa llevar a la práctica uno de los elementos definitorios de los monarcas españoles desde que Alejandro VI, el segundo de los papa Borgia, concede a Isabel y Fernando el título de Reyes Católicos. Esta defensa de la "verdadera religión", institucionalizada por las bulas papales, sin embargo se presentan a la opinión pública y a la posteridad como consustancial a la propia esencia de la historia de los españoles y de la institución monárquica del país, independientemente del origen regnícola de cada uno de ellos. Con esta práctica se inicia un proceso de vinculación de España con el islam y el mundo árabe que será convenientemente utilizada por los diferentes gobernantes hasta los momentos presentes. Todas estas visiones se han fundado, en la mayor parte de las ocasiones, en interpretaciones excesivamente parciales y estereotipadas, tanto en las épocas de visiones positivas como en las de sesgo negativo. De hecho, las empresas magrebíes no se pueden encuadrar ni atribuir a ninguna de las coronas que componen la España del Antiguo Régimen, sino que atañen a todos ellas a lo largo de los siglos. Sólo la ocupación de Melilla, realizada por encargo a un noble, como es el duque de Medina Sidonia, puede tildarse de una acción estrictamente castellana, pero rápidamente volverá a manos del poder central. En el norte de África, y en general en el Mediterráneo, se pueden reseñar armadas organizadas en Cataluña. corsarios en Mallorca y Murcia, factores de varias ciudades andaluzas abasteciendo a plazas españolas y portuguesas, flotas cantábricas atacando ciu- 
dades marroquíes o dependientes del Imperio Otomano, o redentores de cautivos desembarcando en el Grao de Valencia los contingentes de rescatados en Argel o Túnez. Ni siquiera se puede tildar exclusivamente de ser una línea de política exterior del tránsito de la Edad Media a la Moderna, sino que se asocia con el enfrentamiento general con el islam, y éste comienza desde el mismo momento que las tropas de Tariq cruzan Gibraltar y culmina con el fin de la aventura colonial hispana en África.

La falta de adscripción del enfrentamiento con el islam en la Edad Moderna, como la propia definición de la Monarquía, hunde sus raíces en la época medieval. Los musulmanes fueron los que destruyeron el ritmo lógico de la evolución de Hispania, por lo que su enemistad atañe, desde el punto de vista político, a todos los hombres que se vieron afectados por la misma. Además de esta cuestión, más cercana a la esfera del mundo de las ideas que de las realidades concretas, la expansión por el Mediterráneo fue una empresa que en el medievo estaba repartida. Aragón, al concluir con anterioridad la recuperación de los territorios asignados en la "Reconquista" peninsular, se había lanzado a una expansión comercial y pirática por su fachada marítima, iniciada en un primer momento por Cataluña y Mallorca y seguida, en el siglo $X V$, por Valencia. Castilla, por simples cuestiones territoriales, tuvo su primera zona de comercio con los países del norte de Europa, pero cuando se adquieren ciudades en la fachada mediterránea se emprenderán acciones semejantes. Este es el caso de la época de Alfonso X el Sabio y Fernando III cuando llegan a Sevilla y Algeciras y pretenda conquistar Salé (4), o, posteriormente, la existencia de un activo puerto comercial y corsario en Cartagena. En los últimos decenios de la Edad Media el Mediterráneo magrebí entrará claramente dentro de las áreas de influencia de los diferentes reinos cristianos de la Península. La llegada de los portugueses a la ciudad de Ceuta desestabiliza las relaciones de fuerza en los momentos de guerra internas, ya que es una base corsaria que domina todo el estrecho y que puede impedir el normal desarrollo del comercio mediterráneo con los puertos del norte de Europa (5). Ello explica que a la muerte de Isabel la Católica, cuando Fernando vuelve a ser rey de Aragón y simple regente de Castilla, el Mediterráneo siga siendo una empresa común, 
variando sólo la localización de sus intereses. Los castellanos se centran en el norte de África que no corresponde a los portugueses por los tratados de partición de áreas de influencia, y los aragoneses en el sur de Italia, por lo que Fernando pretende atacar Túnez (la ancestral base pirática musulmana del medievo en esta zona del Mediterráneo occidental) para liberar sus posesiones de la presión de estos bandidos del mar (6).

Esta división de áreas de influencia se debe a cuestiones estrictamente defensivas y comerciales, como acabamos de referir, que nuevamente volverán a coincidir cuando, tras la conquista de Orán por Cisneros, se unifique el trono en Carlos I. Por lo tanto, ambas coronas se fijan en el Mediterráneo por móviles mercantiles, por razones de seguridad, tanto de las costas españolas como de las posesiones extrapeninsulares, y por la necesidad de limpiar el mar de corsarios (7).

La coincidencia de intereses atañe exclusivamente al ámbito de la historia política y económica, aunque se cimenta en la existencia de una experiencia semejante, como es el proceso de la "Reconquista" y en la necesidad de una expansión extrapeninsular. En ella, los reinos cristianos se enfrentan a un enemigo común que procede de Asia y África, por lo que ambas zonas son los lugares donde nace el peligro para la Península y, por lo tanto, lugares que desean ser conquistados o sometidos diplomáticamente. Si a esto añadimos que además de una consideración de enemistad política y vital, los musulmanes representan al enemigo religioso, el destructor de "las predicaciones de Cristo en la tierra", contamos con los elementos suficientes para aglutinar en la misma empresa a la mayor parte de los súbditos de la Monarquía durante la Edad Moderna. Pero además el islam, asentado fundamentalmente en Asia y África, está rompiendo el plan original de Dios sobre la organización del mundo y sus habitantes, entendiendo ésta como un cuerpo místico en el que cada continente es una parte del mismo, por lo que su aniquilación es volver a la organización tradicional del plan divino (8).

En los diferentes reinos españoles, pero en especial en Castilla, la línea de fractura entre la civilización y la barbarie no se coloca en las invasiones de los pueblos del norte que acaban con el Imperio Romano, como resulta 
usual en el Renacimiento del resto de Europa, sino cuando uno de ellos, como es el visigodo, es aniquilado o constreñido territorialmente a una estrecha franja montañosa por las huestes árabes. Esta explicación de la historia de España, especialmente evidente en Alonso de Cartagena (9). va a condicionar claramente la posición del pensamiento español sobre la lucha contra el islam. La restitución al orden natural de la situación política en España, que también se puede hacer extensiva al norte de África, pasa por la recuperación de todos los territorios dominados por el mundo romano y el visigodo, por lo que se legaliza y justifica la empresa exterior en el Mediterráneo. De esta manera, Carlos I está emulando las campañas de Julio César, Pompeyo y otros emperadores romanos, a la vez que volviendo a la situación anterior a la derrota de Don Rodrigo. El sometimiento de Granada ha sido el primer paso de esta "restitutio", que debe ser continuada política y religiosamente por los descendientes de los Reyes Católicos (10). La expansión hispana, analizada desde esta óptica, es una simple guerra de restitución llena de ribetes arcaizantes al establecer como fin el ideal de la división política del mundo antiguo. En el Renacimiento español, el culto y el respeto a la Antigüedad tiene dos concepciones diferentes. De un lado, el propio de la corriente cultural que se extiende por Europa en estas mismas décadas, basado en una valoración de la ":nticuetas como elemento de admiración y como modelo de imitación. De otro, la pervivencia de la concepción del Imperio Romano como una unidad política y administrativa a la que hay que tender, unidad que se suele identificar también con el imperio católico después de que el mundo romano se convierte en cristiano. Los visigodos son los continuadores de este orbe político y religioso, por lo que sus sucesores naturales deben dedicarse a la restauración del orden preexistente después de acabar con los impedimentos políticos y territoriales interiores. Esta segunda valoración del "mundo antiguo" occidental permite establecer que las conquistas en el norte de África son una simple restitución de los territorios perdidos con la expansión de los seguidores de Mahoma, a imagen de lo ocurrido en la Península. Es una empresa, por lo tanto, que se justifica en la tradición del mundo romano que procede de la Edad Media, al mismo tiempo que del redescu- 
brimiento de la Antigüedad que están realizando los humanistas. Ya desde los primeros siglos del enfrentamiento con los musulmanes se emplean estos argumentos al referirse a la guerra con los musulmanes, siendo especialmente evidente al relatar choques armados:

Diré toda la historia desde aquel tiempo antiguo en que se dio la tierra el buen rey don Rodrigo, cómo se la ganó el mortal enemigo quedando sin honores como un pobre mendigo. Fue el culpable Mahoma con su mala creencia. pues predicó su boca mucha mala creencia. En cuanto por Mahoma fueron aconsejados sintieron esas gentes los pechos alterados: de la muerte de Cristo estaban olvidados. Desde que los hispanos a cristo conocieron y conforme a su ley bautismo recibieron. a ninguna otra ley nunca tornar quisieron, sino que por guardarla muchos males sufrieron" (11).

En estos versos también se puede apreciar la superposición del concepto de cristiandad con el del Imperio Romano, o sus sucesores los visigodos, por lo que se identifican, y en alguna manera se confunden, los anhelos de recuperación de una estructura política con los de la reunificación religiosa, aunque este tema lo referiré más adelante al reseñar el mantenimiento del ideal de Cruzada en la política africana de los Austrias.

Lno de los caracteres más interesantes de los procesos de expansión por el Mediterráneo es que los turcos otomanos, el nuevo islam enemigo tras el sometimiento de la ciudad de Granada y la conquista de Constantinopla en 1453, va a emplear los mismos argumentos para justificar sus conquistas por Europa, Asia y África. Si con Granada se ha logrado la unidad peninsular, a semejanza del mundo visigodo, la conquista de la ciudad Imperial del otro lado del Mediterráneo por Fatih Sultán Mehmed, es el primer paso para reconstruir el antiguo mundo clásico, por lo que es imprescindible ocupar Roma, la antigua sede del mismo (12). El mundo 
cristiano deseará dominar Jerusalén, el lugar donde vivió el "Redentor", el centro de la creación de la religión, mientras que el sultán otomano querrá controlar Roma, el centro de la mística del poder terrenal, esperanza que se intensifica después de hacerse dueño de Bagdad, Medina y La Meca (13). La conquista del norte de África se puede entender, según estos parámetros, no como una guerra presidida por las ambiciones terrenales; sino el primer paso de la recuperación de un espacio religiosos que se incluyó dentro de un mundo político concreto. Por esta razón se aducirá que todo Marruecos fue evangelizado por San Agustín cuando pertenecía al imperio, realizando fundaciones de iglesias en sus ciudades más importantes, a la vez que el primer paso para recomenzar la empresa que obliga a todo cristiano, la recuperación del Sepulcro de Cristo (14) y el dominio de la Tierra Santa. En el otro lado del Mediterráneo, los otomanos crearán su vinculación con el mundo greco-romano y con Alejandro Magno para legitimar ideológicamente las áreas territoriales donde se establecen y el derecho de poseer Roma.

La conquista de Granada, como luego ocurrirá con las ciudades del norte de África —en especial Orán (15)—, es el contrapeso cristiano a la expansión islámica, estableciendo una especia de ley compensatoria entre el Oriente y el Occidente del Mediterráneo (16). El optimismo con que es recibida en la Europa cristiana la conquista de Granada y las primeras acciones africanas, son la otra cara del pesimismo que deparó unos años antes la pérdida de Constantinopla: "Cuando en el año 1453 se produjo la caída de Constantinopla, Europa entera se sintió amenazada por los turcos, y una serie de profecías y de pronósticos astrológicos anunciaron el triunfo de la 'Lex Alcorani'. En los años siguientes la consternación y el temor no hicieron sino aumentar. Los monjes y otra gente religiosa creyeron en el fin de la cristiandad y en la llegada del Anticristo. Existían también temores más prosaicos, sobre todo entre los gobernantes y las altas jerarquías eclesiásticas, quienes veían peligrar los ingresos proporcionados por el comercio (y las tasas) con los estados balcánicos" (17).

Esta expansión encabezada por los reỵes españoles, como anterioridad lo hicieron los portugueses, les hace presentarse ante el resto de las Monar- 
quías europeas como los baluartes y defensores de la cristiandad asediada por los nuevos enemigos espirituales y morales que han aparecido en el Mediterráneo. Este papel también lo desean representar ante los mismo ofensores, como realizaría Felipe II al incorporar a sus títulos regios el de rey de Jerusalén, y también el monarca francés al incluir el de rey de Nazaret en los encabezamientos de la documentación oficial. Incluso, en la pugna por la proclamación de la Monarquía Hispánica como campeona de la fe ante Francia (18), se esgrimen las diferentes conquistas como elementos reivindicativos. Esta inclusión de títulos acarreará pequeños problemas diplomáticos en los contactos entre la Monarquía y la Sublime Puerta por no ajustarse al reparto territorial de estos siglos. Ello también implica que los españoles, y en general todos los europeos, hallan descrito a los otomanos con unos caracteres de peligrosidad más acentuados que los de los primeros invasores árabes, guerreros más feroces y sanguinarios y con un peso destructivo mayor, tanto a nivel político como religioso, versión que en ningún momento se ajusta a la verdad. Ensalzar al enemigo es engrandecer las victorias propias, lo que representa unos resultados obvios, que incluso han llegado hasta los momentos presentes al referir la importancia de la batalla de Lepanto.

Sin salir fuera de los elementos propiamente escatológicos, se puede incidir en que la reforma emprendida dentro de la Iglesia hispana por Cisneros. como también, y quizá esto sea un atrevimiento excesivo, el propio papel internacional de los Reyes Católicos quedan refrendados por las diferentes conquistas que se están emprendiendo en los restos de Al-Andalus y en el Magreb. Así se puede interpretar el optimismo de los humanistas europeos al conocer la noticia de la toma de Orán. Años más tarde se usará el mismo esquema con la expulsión de los moriscos y la ocupación de Larache por los soldados de Felipe III (19). Y no podemos olvidar que al mismo tiempo que se realiza la empresa africana se desarrolla la evangelización del Nuevo Mundo, en la que también se insiste en los esfuerzos de convertir a la verdadera religión a los indios, idea defendida por el propio iniciador del indigenismo, como es Bartolomé de las Casas. La religión es un elemento justificativo a la vez que una convicción y un sentimiento profundo, así como una 
obligación sentida y aceptada a lo largo de estos siglos. Podría referirse: como simple hipótesis, que las reticencias al abandono de presidios y de la aventura magrebí descansasen en esta cuestión. Tradición, religión, necesidad de crear un escudo defensivo ante posibles invasiones de los musulmanes y prestigio político de recomenzar una empresa presidida por la defensa de la fe son elementos y factores que inciden continuamente en la mayor parte e la acción hispana en África a lo largo de la Edad Moderna.

El islam, y la figura del Profeta, representados tras la pérdida de Constantinopla en los turcos otomanos, no sólo sirven para la lucha por el prestigio de las dos potencias mayores de la cristiandad, sino como elementos esenciales para la propia renovación de los bautizados, como formula el "humanismo cristiano". Todos los reformadores se acercarán a la figura de Mahoma (20) por esta cuestión, siendo especialmente significativa la aptitud de Luis Vives. El islam, renovado en su espíritu destructor por la llegada de los otomanos, es el enemigo de la verdadera revelación, al mismo tiempo que la demostración de los errores que cometen los cristianos en sus creencias. El combate se ha de realizar por medio de las armas materiales, como lo emprenden los monarcas peninsulares, al mismo tiempo que por la mejora de los niveles de práctica y cumplimiento religioso. La lucha contra el infiel es, en sí misma, una empresa que muestra que la cristiandad se está perfeccionando en sus prácticas, por lo que resulta loable a los ojos de cualquier bautizado. Mientras que el enfrentamiento entre cristianos sólo se basa en cuestiones terrenales, desde la óptica religiosa, el que se hace con los musulmanes se fundamenta en cuestiones espirituales, siendo los intereses materiales secundarios en sus formulaciones y en los resultados que se quieren lograr (21). Estos esquemas pertenecen más a la esfera de la justificación que a la de la realidad, ya que la mayor parte de las empresas africanas de la corona están basadas en cuestiones puramente defensivas, estratégicas y. en menor medida, económicas y comerciales; siendo las religiosas e ideológicas legitimadoras de las aspiraciones oficiales y oficialistas. Esto no impide que la lucha con el islam se continuara considerando como la empresa, la guerra por antonomasia, que debe seguir todo bautizado y súbdito de la Monarquía. 
La guerra contra los musulmanes después de la recuperación de Granada ya no se plantea desde la óptica de misión, sino de lucha de legítima defensa por los peligros que acechan. La expansión de los otomanos por los Balcanes y la Europa del Este también crea la sensación de que hay que recuperar territorios a los infieles, tanto en occidente como en oriente. $\mathrm{Si}$ ésta además se emprende en África, resulta más laudable y encomiable, ya que se están atacando las bases mismas del poder de los enemigos. El avance otomano supone que se vuelva a poner de manifiesto y que se revitalice una idea que parecía pertenecer a la plena Edad Media, como es la necesidad de organizar una "Cruzada". Los avances de los otomanos por los Balcanes son intentados contrarrestar por la organización de pequeñas cruzadas en Centroeuropa, que no son capaces de parar una progresión rápida y fulminante de los turcos por zonas que antaño nunca estuvieron amenazadas por los guerreros de la media luna. La mayor parte de las acciones en África y en el Mediterráneo contra la Sublime Puerta se revestirán del mesianismo de la Cruzada (22), e incluso la organización de la Santa Liga que vence a los Turcos en Lepanto es partícipe de estas ideas (23).

Por la recuperación de la ciudad de Jerusalén y el mantenimiento de la guerra contra el infiel se puede justificar cualquier empresa en el Mediterráneo y en el norte de África. Al mismo tiempo que el V Concilio de Letrán (1517) condena a las personas que sostienen que no enfrentarse a los otomanos es contrario a la voluntad de Dios, el "Cristianísimo" rey francés está firmando un acuerdo político con Solimán el Magnífico para aliviar la presión a la que está siendo sometido por los imperiales comandados por Carlos V. Aunque estos datos están fuera de toda duda. tampoco se puede aducir que en el enfrentamiento con los otomanos hay dos bandos perfectamente definidos, ya que todos los Estados tienen miedo al avance turco, aunque muy pocos son los que se oponen directamente y prescinden de su política europea para frenar los progresos de las huestes jenízaras. La lucha contra el enemigo de la religión cristiana, ya sea magrebí u otomano, es una necesidad de los bautizados que se supedita y condiciona a los asuntos más inmediatos e inminentes, razón por la que la empresa africana se abandona rápidamente. Cuando los berberiscos se hagan dueños de las ciudades del 
norte de África, el enfrentamiento con los españoles es inevitable, pero éste se fundamenta sólo en cuestiones defensivas y económicas, aunque se justifica en religiosas y mesiánicas. La Monarquía Hispánica se presenta ante la opinión pública, tanto interior como exterior, como la campeona de la cristiandad en la lucha contra el infiel, al mismo tiempo que abandona toda acción en África ante la defensa del papel hegemónico en Europa o la colonización y exploración del Nuevo Mundo.

El ambiente de los años en los que se verifica el paso del estrecho de Gibraltar, y en general todo el enfrentamiento entre la cristiandad y el islam en los siglos XV al XVII, hay que analizarlo desde una doble perspectiva. De un lado, las cuestiones estratégicas, políticas y económicas, que se reducen al análisis y conocimiento de las directrices y realizaciones de la Monarquía en estas aguas. De otro, el ambiente cultural e ideológico que se vive en Europa y en España en estas mismas fechas. Aunque ambas son inseparables, me centraré sólo en las segundas, ya que las primeras son sobradamente conocidas en sus rasgos esenciales y en sus etapas (24), aunque convendría que fueran estudiadas sin los apasionamientos de la defensa de posiciones políticas y culturales prefijadas y a la luz de nueva documentación. De otra parte, aunque estoy estableciendo un análisis global y general, con todas las limitaciones que ello trae implícito, los intereses españoles se reducen en el espacio y en la significación.

La preocupación de la Monarquía Hispánica es el Imperio Otomano, pero las únicas acciones que se realizan en el Mediterráneo se concentran en el Magreb. Estambul estaba demasiado lejos de las costas levantinas e italianas, por lo que interesa más establecer muros defensivos para impedir la progresión hacia occidente, como puede ser la misma independencia de los territorios marroquíes, que aventurarse a cruzar todo el mar para atacar al antagonista. La reacción de los sultanes otomanos va a ser semejante, como se puede definir el establecimiento de las regencias berberiscas, que mantienen viva y abierta una guerra sin que la metrópoli tenga que desembolsar grandes sumas de dinero.

En los últimos años del siglo XV y los primeros del siglo XVI el mundo occidental comienza a ser asediado por enemigos internos y externos que 
van a desencadenar unas respuestas diferentes a las de los siglos medievales. La pugna con los musulmanes no es la lucha de pequeños poderes territoriales, sino de estados perfectamente constituidos que se enfrentan con otros, igualmente constituidos y perfeccionados. La Guerra de Granada, como la ocupación de Melilla y las otras plazas magrebíes antes de la llegada de los hermanos Barbarroja a Argel, es el último episodio de esta guerra fronteriza y limitada en el tiempo y en el espacio, al mismo momento que la primera manilestación de este cambio (25). La conquista del reino nazari es una confrontación definida por los asedios de las fortalezas, no de batallas a campo abierto, y por el principio de la victoria de cuerpos de ejército perfeccionados y tecnificados (artillería, marina, ingenieros, etc.) (26). Siguen quedando combates singulares, donde el valor de los hombres se pone a prueba por vencer a los enemigos de la fe, acción honrosa para un cristiano, que recuerdan los argumentos del género literario más en boga en estas décadas, como es la novela de caballerías. Esto se mantendrá vivo en el Magreb marroquí, y con unos caracteres diferenciadores en el argelino, hasta finales del siglo XVIl. Cuando Pío II o Erasmo de Roterdam reflexionan sobre el islam no lo hacen refiriéndose a los pequeños reinos islámicos de la europa medieval, sino con la mente puesta en un estado con vocación de imperio que cuenta con un sistema de poder y de organización jurídica e institucional muy jerarquizada que se contrapone a los "Estados Modernos" de la Europa occidental. Los otomanos son la plasmación de un estado supranacional que anexiona todos los territorios que conquista y somete, que se contrapone a pequeños "estados nacionales" presididos por monarquías de corte autoritario o a un Imperio, como es el español, que tiene sus posesiones excesivamente fragmentadas territorialmente. Esta fragmentación es manifiesta en el Magreb y en el norte de Europa, lo que traerá consigo que la aventura africana sea un fracaso por la dificultad de mantener pequeñas posesiones demasiado alejadas de la Península e inconexas entre sí (27). Un mundo turco compacto y uniforme, así como uniformado, tanto geográfica como institucional y políticamente, se enfrenta a una cristiandad fragmentada en sus fuerzas, estructuras, intereses y áreas de influencia. Evidentemente estas diferen- 
cias fueron apreciadas por los hombres de la época, que se referían tanto a la pugna escatológica y religiosa, al mismo tiempo que a la política, como se pone de manifiesto en el propio título de una de las obras de Luis Vives: De europea dissidiis el bello turcico (De la insolidaridad de Europa y de la guerra contra el Turco, 1526).

He referido que entre los países católicos se plantea el enfrentamiento con el islam como la lucha de los campeones de la fe, de adalides de la verdad que deben combatir tanto individual como colectivamente contra el enemigo. Este planteamiento no está demasiado alejado de los manuales de los caballeros, tanto desde el punto de vista militar (28) como del religioso (29). Esta guerra de caballeros, donde las acciones individuales y ejemplares se mantienen vivas, se puede relacionar con el reciente pasado medieval de los litigios de la frontera andaluza, pero también se puede imbricar en los nuevos ideales renacentistas, tanto de corte civil como político y religioso. El jefe de una expedición al norte de África puede equipararse con el adalid medieval que hace una "entrada" en territorio enemigo, con el "caballero aventurero" de las mesnadas medievales, con el "fronteiro" lusitano que somete el atlántico marroquí o con el "condottiero" renacentista italiano (30). Una de las figuras que más contribuye a la expansión hispana en el Magreb, tras la ocupación de Melilla, el conde Pedro Navarro, está más próximo al modelo renacentista de comandante de un grupo armado que al jefe de una mesnada o hueste fronteriza medieval. Sin embargo, la empresa que protagoniza se define por la historiografía tradicional como medieval o arcaizante, o si se quiere, una simple continuación de la guerra culminada con la recuperación de Granada o el mantenimiento del ideal de Cruzada en el siglo XVI. Este personaje, cómo quizá toda la dinámica mediterránea de los primeros años, está incidiendo en que la definición de las empresas entre medievales y renacentistas por el lugar donde se desarrollan es un puro maniquésmo descriptivo realizado a posteriori. Cuando Pedro Navarro deje el bando español para integrarse en el francés será incluido en una de las corrientes, a semejanza de los caballeros de fortuna italianos, haciendo tabla rasa con las empresas dirigidas hasta entonces, como si la conquista de Bugía o el Peñón de Argel fueran 
completamente diferentes a las acciones que realiza al inicio de su carrera militar para los Reyes Católicos en Nápoles y después del paréntesis de las navegaciones mediterráneas para Francisco I. Los primeros Austrias se muestran igualmente orgullosos de sus triunfos en Italia como los que realizan en el norte de África. Todos ellos se relacionan directamente, tanto por su presencia física en el otro lado del Mediterráneo como por sus escritos, en la empresa africana, que reporta tanto prestigio, honor y fama como cualquier otra acción. Incluso más desde el lado religioso, como se aprecia en las representaciones artísticas de exaltación de la Monarquía que tienen como tema de referencia el "triunfo de la fe" contra el islam.

Los musulmanes, tanto otomanos como magrebíes. se adecúan perfectamente a la segunda de las etapas que se describen en la leyenda de la Edad de Oro, completamente en boga en la mayor parte de los textos humanistas (31). Ello responde a que el islam se configura como la antítesis de la propia cultura y religión de los europeos, que atacan los fundamentos esenciales en los que se articula el sistema inteléctico y creencial de la civilización occidental: "Los que sienten una xenofobia tan aguda, los que tal odio y tales ascos experimentan contra el español, el alemán o el francés, ¿por qué no abominan con energía igual del Turco, del escita, de extremada fiereza y barbarie, diferentes, diversos y contrarios en costumbres, idioma, convivencia social, religión?" (32).

El enfrentamiento con el islam, en este caso la amenaza exterior de los europeos, se puede aglutinar bajo el concepto de "cruzada", y también bajo el nuevo espíritu de unificación de la cristiandad propio de los pensadores humanistas. Ambas cuestiones son válidas para los primeros años de la expansión española, triunfando luego la de corte más puramente medieval, como es la de Cruzada. Ello no deja de ser un arcaísmo y un contrasentido evidente, ya que se recurre para oponerse a los otomanos a los mismos argumentos que los usados con los musulmanes, al pensarse que como practican la misma religión y dominaban la Tierra Santa son enemigos semejantes. En el Concilio de Trento nuevamente se volvió a sacar el tema de la unidad de la cristiandad en su lucha contra el Turco como forma de aglutinar voluntades que en principio se plantean contrarias y contrapues- 
tas. El islam, en este caso los otomanos, servirá para mejorar el nivel de los cristianos en su propia práctica religiosa (33), al mismo tiempo que para limar los problemas nacidos en el seno de los bautizados. Aunque este tipo de reflexiones vuelven a ser más intelectuales que materiales, como se pone de manifiesto en las realizaciones prácticas de la política mediterránea. Este argumento también se imbrica con la tradición medieval, ya que se expone en la mayor parte de los procesos de Reconquista, si bien, en estos siglos se le dan argumentos novedosos y renovadas intenciones.

Las intenciones de recuperar Jerusalén y Tierra Santa dan un sentido arcaizante a todo el enfrentamiento, como asimismo a que se recurran a la propia tradición medieval, como se ha reseñado en alguna ocasión en estas páginas, aunque la formulación de tales ideas se realice en circunstancias y por personas que no se pueden tildar de hombres y ambientes de la edad recién finalizada. En la pugna con los musulmanes va a influir más la corriente milenarista que circula en Europa en los siglos XV y XVI, que el propio sentido de Cruzada. Alcanzar la "civitate dei" pasa obligatoriamente por recuperar el origen geográfico de la revelación, de la misma manera que la reconstrucción del mundo clásico lo hace por el dominio de aquellos lugares donde se asentó. El fin del cristiano es lograr la sintonía con las predicaciones de Cristo en materia de fe y los límites de la civilización cristiano-romana, incluido el Santo Sepulcro. La lucha entre las dos religiones se debe emprender, en primer lugar, por la mejora de la condición del cristiano, por el perfeccionamiento individual predicado por el "humanismo cristiano" por medio de la "devotio moderna", y después por la aceptación de los ideales contrarreformistas o reformados. La extinción del enemigo religioso es el fin que depara Dios a sus hijos, tanto desde el punto de vista militar y territorial como desde el creencial. La guerra entre ambos lados del Mediterráneo, que en teoría se fundamenta en cuestiones puramente religiosas; está más imbricada a los motivos políticos que a los escatológicos. Los fundamentos de las empresas de expansión son semejantes a la ideología de Cruzada, como asimismo las formulaciones de estas empresas, pero su desarrollo y los intereses de los participantes no se pueden incluir plenamente en los mismos parámetros que los medievales. La Monarquía Hispánica no es un reino que está 
luchando por recuperar un territorio perdido, sino un imperio que mantiene una pugna con sus vecinos para alcanzar posiciones estratégicas y defensivas más ventajosas. Las "Cruzadas" de la Edad Moderna son guerras en las que entran los "nuevos Estados" con todos sus recursos, por lo que se convierten en intervenciones internacionales para clarificar la situación de un frente militar, más que para expandir la fe cristiana en la tierra de los infieles. Las conquistas en el norte de África pueden incluirse perfectamente en los límites impuestos en las "Cruzadas", como muestra la concesión de las bulas de cruzada por el papado y por la forma con que se presentan ante la sociedad y los sentimientos religiosos que concitan. Los resultados que se logran y los objetivos de la Monarquía, por el contrario, están más cercanos a una guerra de posiciones estratégicas y económicas que a un enfrentamiento religioso.

La expansión española por el norte de África. como el propio enfrentamiento con el islam, genera una dinámica propia, tanto en la esfera de las ideas como de las realizaciones prácticas. De una parte rompen las pretensiones de la Monarquía de crear líneas de posesión estables, como pone de manifiesto la dinámica de plazas fuertes, y de otra, establece su vía propia de evolución en las corrientes de pensamiento de la Europa del momento. Quizá reflexionar sobre la adscripción de esta empresa, y en general de toda la dinámica de Mediterráneo, dentro de las corrientes militares y culturales de la época sea una cuestión absurda y poco fructífera. La guerra se hace como impone el medio donde se desarrolla y el enemigo ante el que se lucha. El enemigo no es el islam otomano ni el magrebí, sino los musulmanes, personas que se definen por su antagonismo religioso, sin especificar muchas más de sus cualidades cognoscitivas y creenciales (34). Aunque los contactos entre las dos culturas y religiones son intensos y traumáticos a lo largo de estas centurias, ello no significa que se culmine con el conocimiento y la comprensión sobre lo que se está describiendo o combatiendo.

La guerra con el islam se adecúa perfectamente al establecimiento de teorías revisionistas sobre la propia sociedad, incluyendo dentro de ella las creencias imperantes en la misma, por lo que se recurre constantemente a la tradición, sobre todo en un país cuya "tradición" se ha forjado luchando contra los musulmanes. El cautiverio cristiano en las ciudades berberiscas se emplea 
para crear nuevos libros de martirologios católicos para reforzar la veracidad de creencias con respecto a los luteranos y reformados (35), y éstos para oponerse, asimismo, a los católicos (36). Algunos miembros del papado para justificar la necesidad de la primacía del poder espiritual sobre el temporal, Pío V lo utilizará para volver a encontrar un elemento de unión entre los bautizados y algunos escritores erasmistas como elemento de ejemplaridad para reformar las propias sociedades cristianas, los dramaturgos españoles para acentuar el papel español dentro de la cristiandad (37) y Miguel de Cervantes para exponer una teoría de la tolerancia y la comprensión (38).

En alguna medida, y como final a unas líneas que han pretendido reflexionar sobre los conceptos y concepciones que existen al mismo momento que se conquistan las ciudades magrebíes, el marco ideológico de la expansión hispana por el otro lado del Mediterráneo es la amalgamación de todas las corrientes en boga en estos siglos, así como el peso ideológico de lo que se cree uno de los elementos esenciales de la constitución de las sociedades nacionales de la Monarquía Hispánica. Aunque existe un modelo prefijado sobre el ambiente de la época, asumido tradicionalmente como marco de referencia suficiente, que se define siempre por el triunfo de la modernidad sobre la tradición, en la visión del islam la modernidad y la tradición se mezclan constantemente. Siempre se ha ponderado más la preeminencia de pasado en esta empresa del presente, pero las personas que la realizan están variando los componentes. El islam en la Edad Moderna era un viejo problema con ribetes nuevos y renovados, la respuesta al mismo va a tener este mismo dualismo. El fracaso de su ejecución por los soldados y las directrices políticas hispanas ha decantado que el juicio global se decantara por la definición de una empresa del pasado, pero eso significa limitar la cuestión a los influjos de una acción abocada a la falta de éxito. Retomar desde unas nuevas perspectivas el análisis de la expansión española por el Mediterráneo supondría conocer mejor aspectos de la historia militar y política hispana, a la vez que entender mejor el ambiente cultural e ideológico de una de las épocas más vigorosas y cambiantes de nuestra historia reciente. 
1. Un análisis sobre la misma, así como un compendio de la misma, la hemes realizado M. CARCÍA-ARENAL, M. A. de BUNES IBARRA y M. V. AGULLAR, Repertorio bibliográfico de las relaciones de la península Ibérica y el norte de Africa (siglos $X V$-XVI). Fiuentes y Bibliografia. Madrid. CSIC, 1989.

2. La hibliografía sobre la expansión hispana por el Magreb siempre pasa por la cita al excelente trabajo de F. BRAUDEL, $L a$ Wediterrunée et le monde méditermuéen à l'époque de Philippe II, París, 1949; y por la referencia al de $A$. C. Hess, The forgotten frontier. A history of the Sixteenth Century. Ibero-African frontier, Chicago-L ondres. 1978. Finsayos más recientes se encuentran en la introducción realizada por $\mathrm{M}$. de EPAL.ZA y J. B. VILAR al libro Planos y mapas hispánicos de Argelia siglos $X V-X V I I I$, Madrid, 1988, documentación completada por los autores en otros volúmenes dedicados a cada una de las divisiones políticas del otro lado del Estrecho, y por $M$.

GARCÍA-ARENAL y M. A. de BI NI:S IBARRA, Los españoles y el norte de Africa, siglos $X V$-XWII, Madrid, 1992. Aunque se pueden seguir citando textos de reciente aparición, no por eso se puede dejar de reconocer el escaso interés que despierta esta cuestión en el panorama historiogrúfico español actual, asi como la necesidad de abordar estudios parciales sobre cada una de las posesiones hispanas en el Magreb y un intento de sistematización de cada uno de los periodos de la presencia hispana en África.

3. M. A. LADERO QUESADO, "El islam, realidad e imaginación en la Baja Edad Media castellana", Coloquio sobre las ufopirs, Madrid, 1990, pp. 215-240; $A$. MAS, Les Tures dans la littérature espagnole du Siècle d'Or, Paris, 1967: S. CARRASCO URGOITI, El moro de Granada en la literatura, Madrid, 1956 (red. Granada, 1991).
4. A. BALIJSSTEROS BARETTA, "La toma de Salé en tiempos de Alfonso X el Subjo", al-Andalus, VIII, (1934), pp. 89-129; . W. GARCíA-ARENAL. "Los moros en las Cantigas de Alfonso X", al-Qantara, 6 , (1985), pp. 133-151.

5. J. GLIRAL-IIADZIIOSSIF, Valencia, puerto mediterráneo en el siglo XV (1410-1525), Valencia, 1989.

6. Gutierre DÍliz DE GAMES, El Victorial, Crónica de Don Pedro, conde de Buelma, Madrid, 1782. En este texto se refiere un episodio acaecido en el puerto de la ciudad de T'úne\%, en el que se destruyen varias naves dedicadas al corso, con el fin de pacificar el Mediterráneo y asegurar el comercio por sus aguas.

7. La concpuista del reino de Granada aumenta el número de las acciones de los corsarios, como consecuencia de la emigración forzosa de los andalusies al norte de África; J. E. LOPEZ E COCA, "Esclavos, alfaqueques y mercaderes en la frontera del mar de Alborán (1490-1516)" Hispania, 38, (1978), pp. 275-300: "Granada y el Magreb: la emigración andalusí (1485-1516)" en Actas del Coloquio: Relaciones de la península bérica y el Magreb, Madrid, (1988), pp. 409-451.

8. "Quien comedir se quier e asmar la fechuras entendrá liome que es razón senpresura. Asia es el corpo. segundo mio creente. sol e luna los ojos que nacen de Oriente; los braços son la cruz del rey omipotente que fue muerto en Asia por amor de la gente.

La pierna que decende del siniestro costado es el regno de Africa por ella figurado: codu la mandan moros, un pueblo renegado, que oran a mafomet, un traedor provado. Es por la pierna diestra Europa notada: ésta es más católica, de la fe más problada: tien en Petrus e Paulus en ella su posada, esu es la diestra del obispo santiguada..." 
Libro de Alaixandre, v. 2508-11.

Cif. Francisco RICO, El pequeño mundo del hombre. Varia fortuna de una idea en las letras españolas, Madrid, Castalia, 1970.

Esta idea se generalizó en la literatura española, como demuestra, la referencia constante a África y Asia como lugares perdidos de la verdadera civilización y fe por su pertenencia a la religión islámica, Miguel Ángel de BUNES IBARRA, "El islam en los Autos Sacramentales de Pedro Galderón de la Barca", Revista de Filologia, LIIl, 105, (1991), pp. 63-84.

9. Alonso de CARTAGENA, "Discurso de Don...., Obispo de Burgos sobre la precedencia del Rey Católico sobre el de Inglaterra en el concilio de Basilea", en Prosistas castellanos del siglo $X V, \mathrm{BAE}, \mathrm{t} .116$.

10. Así lo expone lsabel la Católica en su testamento, legando a los monarcas sucesivos la continuación de la guerra con el infiel.

11. Poema de Fernán González, Ed. Emilio Alarcos Llorach, Madrid, 1982, p. 16.

12. Este miedo se siente especialmente durante el pontificado de los Borgia. La reacción de Roma consistió en evitar el peligro por medios diplomáticos, concediendo asilo y protección al príncipe Cem para impedir el paso de las huestes otomanas de las costas dálmatas a las italianas.

13. H. INALCIK, The Ottoman Empire. The Classical Age, 1300-1600, Londres, 1973; M. F. KÖPRÜLÜ, The Origins of the Ottoman Empire, Nueva York, 1992.

14. Martín Dámpies en la crónica de Bernardo de Braindenbach, Viaje de Ia Tierra Santa, Zaragoza, 1498, incluye unas páginas en las que reficre los emperadores romanos, que pueden ser interpretadas como la simple referencia de un humanista o relacionarlas con establecimiento de una vinculación de la Monarquía Católica con Palestina.
15. Así se pone de manifiesto en la carta que Charles de Bovelles envía al cardenal Cisneros para felicitarlo por su conquista: "Has sabido vencer: tienes que saber aprovechar la victoria. Has tomado en tu mano el arado: no vuelvas atrás tus miradas hasta que los surcos africanos queden llenos de la divina simiente. Has comenzado a hacer violencia al reino de los cielos, pues éste sufre violencia. No cejes, no descanses hasta penetrar en él. por el legítimo favor de Dios y hasta que tome posesión de él, contigo, el innumerable y glorioso ejército de Cristo. Abre a los adoradores de Cristo el camino por donde, sin peligro, a través de las naciones fieles y obedientes a Dios, sea posible alcanzar y visitar los lugares sacrosantos en donde el Señor fue inmolado". Cif. M. BATAILLON, Erasmo y España, México, 1979, pp. 56-57. Este texto se ha interpretado como una incitación a la vuelta al espíritu de Cruzada, y al mesianismo católico en su lucha contra el infiel. Las conquistas españolas en el Magreb adquieren una significación mucho mayor que en épocas anteriores en Europa, dado que el continentc está amenazado por los turcos, lo cual cambia completamente la situación existente en los siglos medievales.

16. El optimismo generado por la conquista de Granada no sólo se produce en España, sino en toda la Cristiandad. En Italia, por el miedo a la invasión turca, el triunfo es celebrado con especial énfasis, cuestión a la que no es ajeno que el solio pontificio repose en la testa de un español. En las comedias humanistas que se escriben para los fastos del acontecimiento se suclen incluir las reacciones del sultán de Estambul, como refiere M". D. RINCÓN GONZÁLEZ, en su estudio sobre la Historia Baetica de Carlo Verardi (Drama humanístico sobre la toma de Granada), Granada, 1992, pp. 60 y 78.

17. Ottavio DI CAMILO, El humanismo castellano del siglo $X V$, Valencia, 1976, p. 
197. En la nota adjunta especifica cuál es la reacción de los escritores españoles del momento: "El pánico que sobrecogió a Europa fue particularmente sentido en España, donde una resurgencia árabe habría desecho lo que los reyes cristianos habian conseguido durante siglos de guerras. La reacción a esta amenaza revistió una forma de satisfacción con el desorden político y civil, y es en este clima que Santillana escribe su Lamentación en prophecia de la segunda destruycion de España, ... Véase también Pérez de Guzmán, Respuestas fechas al marqués de Santillana, sobre la destruyción de Constantinopla, ... En la misma línea está también el anónimo Libro de la consolación de España,...".

Carlo Verardi en su Historia Baetica..., va más lejos en esta formulación del optimismo cristiano por la recuperación de Granada: "in hostium tuorum, immo communium, ditionem iusque concessisse, metuendum que esse, nisi tibi, aliunde succurratur ignominia, aut histi succumnas, aut turpern deditionem facere imminuatur, facile posse latius diffundi, et. Africam primo, deinde atiam Asiam fortasse corriepere, statuir ad commune incendium comminibus quoque viribus arcurrere, et pro virili parte tibi regnoque tuo, qua posset ope, non decsee", p. 78.

18. El enfrentamiento cntre Francia y España por la primogenitura en la defensa de la Cristiandad ha sido estudiado por $\mathrm{A}$. MILHOU, Colón y su mentalidad mesiánica en el ambiente franciscanista español, Valladolid, 1983.

19. J. L. ROJAS, Relaciones de algunos sucesos postreros de Berbería. Salida de los moriscos de España y entrega a Alarache, Lisboa, 1613.

20. N. Daniel, Islam and the West. The Making of an image, Edimburgo, 1966.

21. La guerra contra el islam se adecúa perfectamente a las consideraciones de "guerra justa" fijadas por Santo Tomás de Aquino en su Summa Theologica.

22. N. HOUSIEY, The laters Crisades, Londres, 1992.

23. E. GARCÍA HERNÁN, "Pío V y el mesianismo profético". Hispania Sacra, 45, (1993), 91, pp. 51-71.

24. F. BRAUDEL, "Les espagnols et l'Afrique du Nord, de 1492 à $1577^{\text {n }}$. Revue Africaine, 69. (1928), pp. 184-233 y 351-410.

25. M. A. LADERO QUESADA. Castilla y la conquista del reino de Granada, Valladolid, 1967. En estas páginas se refiere cómo los Reyes Católicos alentaron las ideas y sentimientos populares de Cruzada, a la vez. que lograban concesiones de los papas para incrementar las arcas del estado con algunas rentas eclesiásticas, práctica que seguirán el resto de los Austrias.

26. "Peor es, si consideras el modo con que se hacen guerra, no con espada, ni lanza, ni ballesta, de forma que una herida, cuando es mortal, mata a un solo hombre. Han hallado una manera nueva, cuyo estampido produce estruendo mayor que Júpiter cuando truena; un solo de sus disparos derriba hombres, de veinte en veinte, de cuarenta en cuarenta, de ciento en ciento", Juan Luis VIVES. De la insolidaridad de Europa, T. II, p. 50.

27. R. RICARD, "Le problème de l'occupation restreinte dans l"Afrique du Nord (XVe-XVlle siècles)", Annales d'Histoire Economique et Sorial, 8, (1936), pp. 426-437. La idea primitiva del paso al otro lado del Estrecho era constituir un territorio autosuficiente y amplio, pero la realidad africana les impuso el sistema de presidios que, a la postre, impedirá el avance de las conquistas en el Magreb.

28. Ramon LLull, Llibre de l'Orde de Cavalleria, Ed. Marina Gustà, Barcelona, 1989. 
29. En los textos de los pensadores eclesiásticos suele ser corriente la utilización en los títulos de sus obras de manual del caballero cristiano, comenzando por el propio texio de Erasmo, lo que nos pone de manifiesto el concepto de depuración de la fe que preside la época.

30. E. GARIV y otros, El hombre del Renacimiento, Madrid, 1990.

31. "Y en esta edad nuestra de hierro nombrada,

Sin orden alguno, sin regla, sin modo, Ya todo es confuso, borracho va todo, De estado ninguno no hay que fiar nada, Sobervia, Avaricia, Lujuria es usada, Ira, Gula, Invidia y Acidia despierta, Virtud es dormida, Bondad es ya muerta, Verdad, fuese al Cielo, ya va desterrada". Juan de la ENCINA, Viaje y peregrinación que hizo y escribió en verso castellano el famoso poeta... en compañía del marqués de Tarifa, en que refiero lo más particular de lo sucedido en su Viaje, $y$ Santos Lugares de Jerusalén, Madrid, 1786, p. 1.

32. Juan Luis VIVES, De conditione vitae christianorum sub Turca, (1526), Obras Completas, T. II, p. 67.

33. Esto mismo lo realiza el autor anónimo del Viaje de Turquía en los primeros años del siglo XVI. La exaltación de lo que se considera cercana a la barbaric para mostrar y poner en evidencia los defectos propios.

34. M. A. de BUNES IBARRA, La imagen de los musulmanes y del norte de Africa en la España de los siglos XV y XVII. Los caracteres de una hostilidad, Madrid, 1989.

35. Diego de HAEDO, Topografia e historia general de Argel, Valladolid, 1612, el capítulo dedicado a los martirologios de los cristianos en Argel acaba de ser reeditado por E. Sola y J. M. Parreño, atribuyendo la autoría del texto a Antonio de SOSA, con el título de Diálogo de los mártires de Argel, Madrid, 1990; G. TURBET-DFLOF, L'Afrique barbaresque dans la littérature française, 1532-1715, Genève, 1974.

36. Cipriano VALERA, Tratado para confirmar en la fe cristiana a los cautivos de Berberia, .... Madrid, 1827.

37. M. A. de BLNES IBARRA, "El islam en los Autos Sacramentales de Pedro Calderón de la Barca", Revista de Literatura, LIII, 105 (1991), 63-84.

38. Como se pone de manifiesto en la comedia titulada La Gran Sultana, texto que gracias a una representación teatral reciente ha sido sacado del olvido injustificable en el que se encontraba. 